\title{
Installation of mechanical ventilation in a horse stable: effects on air quality and human and equine airways
}

\author{
Robert Wålinder • Miia Riihimäki • \\ Susanne Bohlin • Carl Hogstedt • Tobias Nordquist • \\ Amanda Raine · John Pringle • Lena Elfman
}

Received: 30 June 2010/ Accepted: 8 November 2010/Published online: 25 December 2010

(c) The Japanese Society for Hygiene 2010

\begin{abstract}
Objectives To examine the effects of installing a mechanical ventilation system at a riding-school stable on indoor air quality and human and horse airways.

Methods The intervention was the installation of mechanical ventilation in a riding-school stable. Carbon dioxide $\left(\mathrm{CO}_{2}\right)$, ammonia, particles, horse allergen, microorganisms and endotoxins were measured in the stable. The stable-workers and riding-students completed a questionnaire and underwent the following tests: analysis of nasal lavage for inflammation biomarkers; levels of exhaled nitrogen oxide (NO); measurements of daily peak-expiratory flow (PEF). The horses were examined clinically by airway endoscopy and bronchoalveolar lavage (BAL) and were analysed for cytology and biomarkers.

Results Levels of $\mathrm{CO}_{2}$ were nearly halved and airborne horse allergen levels were markedly reduced $\left(5-0.8 \mathrm{kU} / \mathrm{m}^{3}\right)$ after the intervention. A decreased level of ultrafine particles was observed (8000-5400 particles $\left./ \mathrm{cm}^{3}\right)$ after the
\end{abstract}

R. Wålinder $(\bowtie) \cdot$ S. Bohlin · C. Hogstedt · T. Nordquist .

L. Elfman

Department of Medical Sciences, Occupational and

Environmental Medicine, Uppsala University Hospital,

University of Uppsala, 75185 Uppsala, Sweden

e-mail: robert.walinder@medsci.uu.se

M. Riihimäki · J. Pringle

Department of Clinical Sciences, Section of Large Animal

Surgery and Medicine, Equine Internal Medicine, Swedish

University of Agricultural Sciences, 75007 Uppsala, Sweden

A. Raine

Department of Cell and Molecular Biology,

Uppsala University, 75105 Uppsala, Sweden intervention, while total and respirable dust levels were mainly unchanged (200 and $130 \mu \mathrm{g} / \mathrm{m}^{3}$ ). Levels of microorganisms in surface samples decreased following the intervention, whereas airborne microorganisms and endotoxin increased. There was no significant change in human symptoms, PEF-variability, exhaled NO or inflammatory biomarkers in the nasal lavage. In horses, the mean score of lower airway mucus was significantly reduced together with the mean level of expression of interleukin- 6 mRNA in BAL cells after the intervention.

Conclusions The installation of a mechanical ventilation system resulted in an increased air exchange rate, as demonstrated by reduced levels of $\mathrm{CO}_{2}$, ammonia, ultrafine particles and horse allergen. There was no significant clinical effect on human airways, but there was a tendency for reduced inflammation markers. The results on the horses may indicate less impact on their airways after the intervention.

Keywords Airways · Biomarker · Horse · Human · Indoor air quality

\section{Introduction}

In intensive agricultural practices involving cows, pigs and poultry there is considerable evidence that farmers and farm workers, who spend large parts of their days in the barn environment, are at increased risk of developing respiratory diseases [1-4]. In Sweden, farming is one of the occupations associated with the highest prevalence of asthma [4]. Farm buildings with confined housing of domesticated animals, regardless of the species, contain a wide variety of gases and organic dusts in the atmosphere, including microbes and the products thereof, such as endotoxins and 1-3- $\beta$-glucans $[5,6]$. 
It is well known that exposure to the organic dusts, microorganisms and endotoxins present in different farm animal stabling systems can cause chronic pulmonary diseases in humans [7-9].

In industrialized countries, large numbers of people work in the equine industry, with many of these actively coming into close contact with horses. There are 28,000 full-time jobs in the equine industry in Sweden, and it has been estimated that 4.6 million Americans in the USA are directly involved in that country's equine industry (American Horse Council Foundation 2005: Economic impacts of the US horse industry). Many people spend a considerable amount of time each day in equine stable environments, either as employees involved in the care and training of horses or as a leisure activity (for example, $6 \%$ of the Swedish population).

Similar to other farming environments, horse stable air also contains a plethora of inorganic and organic particles that are potential airway allergens and irritants. Specifically, the organic portion that often originates from feed, bedding or manure or from growth on stable walls [10], such as bacteria and fungi (e.g. Faenia rectivirgula, Aspergillus fumigatus) or their products, can be found in high amounts in the stable air [11]. Studies in conventional horse stables have shown that acceptable levels of endotoxin and 1-3- $\beta$-glucan, which may cause inflammation in human airways, are often exceeded [10, 12]. Until recently, however, the influence of equine stable air on human health has been relatively ignored.

Increased contact with horses has been related to an increased incidence of asthma and decreased pulmonary function in grooms [13]. Several recent surveys based on self-reporting data have also identified an increased risk of respiratory symptoms in people with high exposure to equine barn air [14, 15]. In addition to this risk to human health, indoor stable air is a well-established trigger of airway inflammation in horses with the asthma-like disease "recurrent airway obstruction" (RAO) [6] and even in clinically normal horses [16].

To the best of our knowledge, no data have been published that relate detailed measurements of stable air quality and respiratory health measurements in stable personnel and horses in the same stable. We hypothesized that selected components of stable air environment measurements in horse stables could be correlated to indices of respiratory health in individuals spending a considerable amount of time in the stable environment as well as in the stabled horses. We therefore conducted an intervention study in which markers of respiratory health in people and horses, as well as stable air quality indices, were measured longitudinally before and after the installation of a mechanical ventilation system in a previously naturally ventilated stable.
The hypotheses that we specifically tested were:

1. The particulate and gaseous makeup of stable air would measurably differ from that of a naturally ventilated equine stable following the installation of mechanical ventilation.

2. The indices of respiratory health in stable personnel and in stabled horses would be measurably improved following the installation of mechanical ventilation in the stable.

\section{Methods}

Study design

\section{Intervention}

A balanced supply and exhaust ventilation system was fitted in a former naturally ventilated riding-school stable. The supply air came in from the outer wall in the middle of the building and was distributed via outlets from the ceiling into 18 of 24 horse-boxes. The exhaust air was pumped out through a vent-canal placed in the middle of the stable corridor that passed up through the hay-loft to the top of the roof (Fig. 1). The ventilation system was scaled for occupancy of 25 horses, and the airflow was regulated by the indoor temperature and adjusted for a maximal flow of $2200 \mathrm{~L} / \mathrm{s}$ under summer conditions and a minimal flow of $400-550 \mathrm{~L} / \mathrm{s}$ during the winter at a temperature of $5^{\circ} \mathrm{C}$ in the stable. Measurements were performed three times within a 1-year period: in the winter before the intervention; in the summer before the intervention; in the following winter after the intervention (hereafter referred to as Round 1, Round 2, and Round 3, respectively). The installation of mechanical ventilation was performed in February the year after the first measurements (Round 1 and 2) were performed. Round 3 measurements (after the intervention) were performed in early April when the new mechanical ventilation system had been running-and personnel and horses had been exposed to these new indoor stable conditions-for 1 month. The evaluations (both before and after the intervention) consisted of hygienic measurements of indoor air quality and clinical examinations of both humans and horses.

\section{Building}

The horse stable, built in the 1920 s, was run by a communal riding school. It was a concrete frame building with a concrete floor and metal roof $\left(12 \times 30 \mathrm{~m}^{2}\right)$, without supplemental heating or mechanical ventilation. The horseboxes were separated by wooden plank walls with upper 


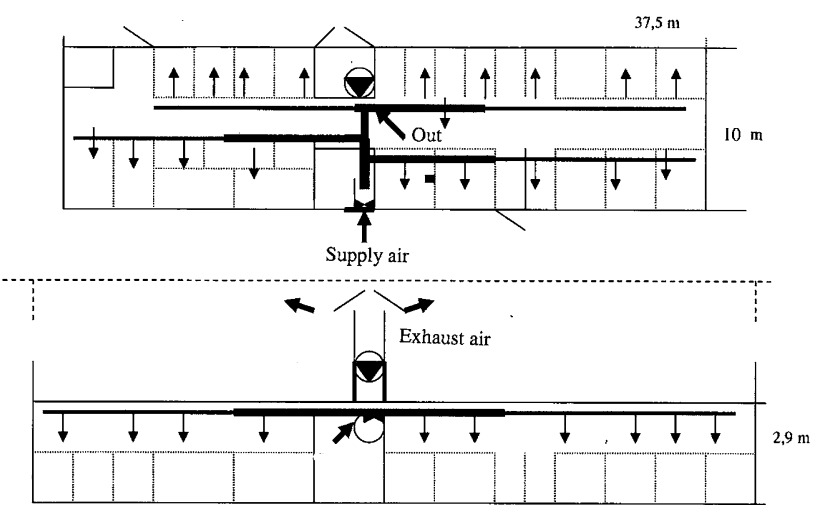

Fig. 1 Scheme of the mechanical ventilation system installed in the riding-school stable

steel bars and with sliding doors of the same construction. There were four entrances to the stable; one at each end of the building and two on one of the long sides, of which one was used for removing manure while cleaning, and the other was used to take horses in and out to the adjacent riding hall. There was a loft above the stalls and under the roof where hay and straw were stored.

The stable housed a total of 24 horses of mixed breeds. A normal day's activities at the stable consisted of the following. The boxes or stalls were mucked-out by stablepersonnel each morning after the horses had been taken outdoors. Fresh straw for bedding was taken down from the loft via a hole in the ceiling inside the stable and distributed to the boxes. Doors were generally kept open during the cleaning of the stable and during training sessions. Horses were fed three times a day (in the morning before going out to the fields, at midday when coming back to the stables prior to the training sessions and in the evening) with haylage and pelleted fodder. Riding classes were held between 4:00 p.m. and 9:00 p.m., which means horses were groomed and made ready for riding, and people and horses were coming and going on an hourly basis.

\section{Hygienic measurements}

At each of the three rounds, we carried out hygienic sampling on two successive days. In order to obtain peak exposure values, the samplings were conducted over a period of 4-7 h, beginning at 7:00 a.m., when routine morning activities were being carried out in the stable, such as cleaning the stalls, and continuing into the afternoon, when the horses were being fed, groomed and trained. Some overnight samples were also taken when all the horses were in the stables and doors were closed.

Real-time monitoring of carbon dioxide $\left(\mathrm{CO}_{2}\right)$, temperature, humidity, ultrafine particles and coarse particulate matter $\left(\mathrm{PM}_{10}\right)$ was made continuously for $30-37 \mathrm{~h}$ during the 2 days of sampling at each round. The sampling point was in the middle of the stable corridor. $\mathrm{CO}_{2}$, temperature, and relative humidity (RH\%) were logged every minute with a Q-Trak (model 8550; TSI, Shoreview, MI) up to $37 \mathrm{~h}$.

Monitoring of ultrafine particles, defined as particles with a diameter of $<0.1 \mu \mathrm{m}$ (range $0.02-1 \mu \mathrm{m}$ ) was performed with a P-Trak (model 8525; TSI), logging data every minute over a period of $12-37 \mathrm{~h}$. Measured data are presented as particles per cubic centimetre.

A DustTrak aerosol monitor (model 8520; TSI) was used to measure airborne dust concentration (ADC, particles $<10 \mu \mathrm{m}$ ), which was programmed to log measured data every minute over a period of 28-37 h. Concentrations are presented as milligrams per cubic metre. All logged data were downloaded after sampling using TrakPro v3.33 software for data analysis. A graphical display of time versus temperature, $\mathrm{RH} \%$, and $\mathrm{CO}_{2}$ or $\mathrm{ADC}$ and ultrafine particles, respectively, was constructed to provide a visual indication of the timing and duration of peak concentrations and their relation to activities in the stable.

Measurements of ammonia in the air were obtained using passive samplers during three different 24-h periods in 1 week. Samples were analysed at The Swedish Environmental Research Institute, Gothenburg, Sweden [17]. The values are expressed as micrograms per cubic metre and are the median of three samples. However, no sample was available for Round 1 because of the authors' unawareness of the method at the time.

Air sampling was performed with pumps (SKC, EightyFour, PA) for sampling of horse allergen, total and respirable dust, airborne microorganisms, and endotoxins. In general, three samples of each factor were collected at each sampling round. Pumps were adjusted for a flow of $2 \mathrm{~L} /$ min for $4-7 \mathrm{~h}$ and placed approximately $1-1.5 \mathrm{~m}$ above ground level at three points in the stable corridor, one near to each end and one in the middle, immediately outside a stall, with the filter unit attached to the steel bars. Airborne horse allergen particles were collected with an IOM-sampler (SKC) equipped with a fluoropore membrane filter (pore size $1.0 \mu \mathrm{m}$, Type FA; Millipore AB, Sweden). Air samples were analysed for horse allergen levels using a two-site sandwich enzyme-linked immunosorbent assay (ELISA; monoclonal antibodies from Mabtech $\mathrm{AB}$, Stockholm, Sweden) [18] and expressed as units per cubic metre, where 1 unit is equal to $1 \mathrm{ng}$ protein of a horsehair, and dander extract was used as a standard (Allergon, Valinge, Sweden). The detection limit for the assay was $2 \mathrm{U} / \mathrm{ml}$, which was the equivalent of $2 \mathrm{U} / \mathrm{m}^{3}$.

Total and respirable dust in air was collected in a cassette with a $25-\mathrm{mm}$ (pore size $0.8 \mu \mathrm{m}$ ) membrane filter. In the case of respirable dust, a metal cyclone (SKC) was placed before the filter cassette, and the pump was attached to the personnel's clothing or to the horse's back, with the 
inlet of the tubing in the breathing zone. All airborne dust samples were analysed by a gravimetric method and the organic proportion calculated after combustion of the filter and weighing of the remaining inorganic material (Occupational and Environmental Medicine Laboratory, Orebro University Hospital, Sweden). The detection limit was $0.1 \mathrm{mg} / \mathrm{sample}$, and results are expressed as milligrams per cubic metre.

Samples of airborne microorganisms and endotoxin were collected on a cassette with a $25-\mathrm{mm}$ sterile nucleopore filter (pore size $0.4 \mu \mathrm{m})$. Surface sampling $(90 \times$ $65 \mathrm{~mm}, 0.006 \mathrm{~m}^{2}$ ) was performed using Scotch-brite on the outer wall of three stalls at about $1.5 \mathrm{~m}$ above the floor. The total concentration of airborne and surface moulds and bacteria were analysed with the CAMNEA method [19] based on acridine orange staining and epifluorescence microscopy (performed by Pegasus Lab; Eurofins Environment Sweden AB, Sweden). Species of viable moulds and bacteria were determined by incubation on two different media [20]. The incubation time was 7 days on both media and for all microorganisms with the exception of Streptomyces $\mathrm{sp}$. for which the incubation time was 21 days. The detection limit for viable organisms was 30 colony forming units $(\mathrm{CFU}) / \mathrm{m}^{3}$ of air.

For the analysis of endotoxin, the filters were extracted with pyrogen-free water and analysed at the Department of Clinical Microbiology and Infection Control, Uppsala University, using the kinetic turbidimetric method with the Limulus test (Cape Cod, MA and Endosafe (Charles River Endosafe, Charleston, SC). The results are expressed as EU per cubic metre.

\section{Investigation of humans}

At the start of this study the stable personnel comprised six women and one man and approximately 320 students between the ages of 7 and 18 years who were attending the riding school. Initially, all seven personnel agreed to participate. However, one male employee dropped out of the study during the first sampling round, and one female employee left before the second sampling round. For practical reasons, only students $>12$ years of age and who were at the stables at least several days a week were asked to participate. In total, seven students (6 girls and one boy) provided their own written consent to participate, after obtaining permission from their parents. Stable personnel and riding-students completed a questionnaire on the annoyance of dust and smell in the stable and on symptoms of eczema, eye irritation, nasal congestion and dyspnea. Lung function was measured by spirometry (Spirobank G; Mir, Rome, Italy) according to American Thoracic Society (ATS) standards [21], and measurements of nitrogen oxide (NO; NIOX MINO; Aerocrine AB, Solna, Sweden) were performed on the days the hygienic measurements were being made. Subjects were instructed to make repeated peak expiratory flow (PEF) measurements using a Piko-1 electronic device (Medeca Pharma, Uppsala, Sweden) and forced expiratory volume in $1 \mathrm{~s}$ (FEV1) measurements four times per day for 2 weeks [22].

Lavage of the nasal mucosa was performed by introducing $5 \mathrm{ml} 0.9 \%$ sterile saline solution in each nasal cavity [23]. The biomarkers analysed in the nasal lavage fluid included eosinophil cationic protein (ECP) (a marker of eosinophil activity) [24], myeloperoxidase (MPO) of the neutrophils in the mucosa [25], lysozyme (a marker of neutrophil activity and secretion from parasympathetically innervated mucosal glands) [26], albumin (a marker of capillary leakage of plasma proteins) [27], interleukin (IL)5 (a marker of eosinophil and Th2 activity) and interferongamma (IFN- $\gamma$ ) a marker of Th1 activity [28]. ECP, MPO, lysozyme and albumin were analysed at the Department of Clinical Chemistry, University Hospital of Uppsala by methods described elsewhere [23]. IL-5 and IFN- $\gamma$ were analysed using ELISA kits according to the instructions of the supplier (R\&D Systems Europe, Abingdon, UK) at the Department of Occupational and Environmental Medicine, University Hospital of Uppsala.

Investigation of horses

Of the 24 horses of different breeds in the riding-school stable, 14 were included in the study. The initial selection was based on the probability that they would remain in the stable during the entire 1-year study. However, ultimately only eight of these 14 horses remained during the whole study period [six mixed breed ponies and two warmblood horses, all geldings; aged $12.5 \pm 2.7$ years, mean \pm standard deviation (SD); range 8-16 years]. All horses were examined at the riding school stable, and the tests included a clinical respiratory examination (pulmonary auscultation with and without re-breathing bag and cough provocation), routine blood sample analysis, upper and lower airway endoscopy and bronchoalveolar lavage (BAL) using a blind tube (Surgivet, Waukesha, WI) according to published methods [29]. The recovered BAL fluid was placed on ice; a 30-ml sample was removed for immediate processing for cytological examination using the cytospin technique as previously described, and the remainder was prepared and stored for quantitative real-time multiplex PCR analysis for IL-6, IL-8 and IL-10 mRNA at the Department of Cell and Molecular Biology, Uppsala University using the QuantiTect Multiplex PCR NoROX kit (Qiagen, Hilden, Germany). The PCR cytokine mRNA expression for individual horses was calculated in relation to a theoretic median value of $1\left(\Delta \Delta C_{\mathrm{T}}=0,2^{-\Delta \Delta C_{\mathrm{T}}}=2^{0}=1\right)$ [29]. The $\Delta C_{\mathrm{T}}$ value is the difference between the $C_{\mathrm{T}}$ value for the 
target gene and reference gene, and the $\Delta \Delta C_{\mathrm{T}}$ value is the difference between $\Delta C_{\mathrm{T}}$ values that are compared in Fig. 3 .

\section{Statistics}

Hygienic measurements and clinical data were calculated as mean or median values and, where appropriate, with 10th and 90th percentiles. For particle data, the 98th percentile is also given. The Wilcoxon matched pairs test was performed to compare clinical parameters before (stable with natural ventilation) and after the intervention (stable with mechanical ventilation).

\section{Ethics}

The human study was approved by the regional ethics committee at the University of Uppsala, Sweden (Ups 03649). The study on horses was approved by the Ethical Committee for Animal Experiments, Uppsala, Sweden (diary number $\mathrm{C} 16 / 7$ ).

\section{Results}

\section{Hygienic effects of the intervention}

The median level of $\mathrm{CO}_{2}$ in the stable during winter season was reduced from $950 \mathrm{ppm}$ before the intervention to $510 \mathrm{ppm}$ afterwards (Table 1). Before the intervention, the median summer value was 800 ppm. In Fig. $2 \mathrm{CO}_{2}$ is plotted over time for each round. Measurements for Round 1 were not complete within $24 \mathrm{~h}$ due to instrument malfunction. The 90th percentile for Round 1, 2 and 3 was 1280, 900 and $750 \mathrm{ppm}$, respectively; the 98th percentile for Round 1, 2 and 3 was 1410, 980 and 810 ppm, respectively. The median level of ammonia was reduced from $3200 \mu \mathrm{g} / \mathrm{m}^{3}$ before the intervention to $1330 \mu \mathrm{g} / \mathrm{m}^{3}$ after installation of the mechanical ventilation system (Table 1). Relative humidity over $24 \mathrm{~h}$ varied between 40 and 84 $\mathrm{RH} \%$ at the first winter sampling (Round 1) and varied between 58 and 97 RH\% during the winter after the intervention; summer values ranged between 65 and $84 \mathrm{RH} \%$.

The mean temperature in the stable at the winter sampling before and after the intervention was $8^{\circ} \mathrm{C}$ (range $7-15^{\circ} \mathrm{C}$ ) and $8^{\circ} \mathrm{C}$ (range $6-12^{\circ} \mathrm{C}$ ), respectively. At the summer measurement (Round 2) the mean temperature was $21^{\circ} \mathrm{C}$ both in the stable and outside.

No real difference was detected in total dust due to the intervention. Prior to the intervention, the median total dust level was $210 \mu \mathrm{g} / \mathrm{m}^{3}$ in the winter and $220 \mu \mathrm{g} / \mathrm{m}^{3}$ in the summer; in the winter following the intervention, it was $200 \mu \mathrm{g} / \mathrm{m}^{3}$. The median respirable dust level was also not reduced by the intervention, being 100 and $130 \mu \mathrm{g} / \mathrm{m}^{3}$ in the winter before and after the intervention, respectively; the intermittent summer value was somewhat lower at $70 \mu \mathrm{g} / \mathrm{m}^{3}$. The effect of the intervention on the $\mathrm{PM}_{10}$ level could not be evaluated at the winter sampling before the intervention due to a technical error. The summer value before the intervention was somewhat lower $\left(53 \mu \mathrm{g} / \mathrm{m}^{3}\right)$ than the median winter value after the intervention $\left(65 \mu \mathrm{g} / \mathrm{m}^{3}\right)$.

The median level of ultrafine particles was reduced from 8000 particles $(\mathrm{Pt}) / \mathrm{cm}^{3}$ before the intervention to $5400 \mathrm{Pt} /$ $\mathrm{cm}^{3}$ after the intervention. The median summer value was $1500 \mathrm{Pt} / \mathrm{cm}^{3}$. The 98th percentile for ultrafine particles showed the same pattern. The median horse allergen level in the stable air was $5170 \mathrm{U} / \mathrm{m}^{3}$ the winter before the intervention, falling to $790 \mathrm{U} / \mathrm{m}^{3}$ in the winter after the intervention. The median summer value before the intervention was $750 \mathrm{U} / \mathrm{m}^{3}$.

The number of microorganisms on the inner wall surfaces fell after the intervention, with the number of bacteria falling from $110 \times 10^{5}-1.4 \times 10^{5} / \mathrm{m}^{2}$ and that of fungi, from $6.6 \times 10^{5}-0.15 \times 10^{5} / \mathrm{m}^{2}$. The summer values before the intervention were in the same range as the winter values after the intervention. The total number of bacteria in air samples was almost the same in all three rounds: $19 \times 10^{5} / \mathrm{m}^{3}$ before and $21 \times 10^{5} / \mathrm{m}^{3}$ after the intervention, while the total number of fungi increased from $3.5 \times 10^{5} / \mathrm{m}^{3}$ before the intervention to $6.6 \times 10^{5} / \mathrm{m}^{3}$ after the intervention. Summer values were lower. Median endotoxin levels in air increased substantially after the intervention (from 96 to $\left.275 \mathrm{EU} / \mathrm{m}^{3}\right)$.

\section{Effects of intervention on human health}

The mean age of the stable personnel and riding-students was 34 (range 21-51) and 15 years (range 13-17 years), respectively. One student smoked. None of the employees or students reported asthma, but one employee had used asthma medication symptomatically before the intervention, but not thereafter. Two students reported suffering from hay-fever. Reports of smell-discomfort, annoyance to dust, eczema, eye irritation, nasal congestion and dyspnoea were unchanged after the intervention. The results of pulmonary function tests were within normal limits according to gender, age, weight and height [30, 31]. Daily PEF measurements were not significantly changed after the intervention among the stable personnel (Table 2). However, there was an increase, albeit not significant, in pulmonary function among the students (Table 2), with the mean PEF level increasing from 387 to $416 \mathrm{~L} / \mathrm{min}$ and FEV1 increasing from 2.9 to $3.2 \mathrm{~L} / \mathrm{s}$. This is most likely due to the growth of the students. Exhaled NO values were low and remained at the same level on all three sampling occasions. The median level of inflammation markers in nasal lavage was not significantly altered after the intervention (Table 2). 
Table 1 Hygienic measurements in the riding-school stable

\begin{tabular}{|c|c|c|c|c|c|}
\hline Parameters & Round 1 & Round 2 & Round 3 & Unit & Calculated as: \\
\hline \multicolumn{6}{|l|}{$\mathrm{CO}_{2}$} \\
\hline In stable & $990(550-1280)$ & $800(670-900)$ & $510(350-750)$ & ppm & Median (10th-90th percentile) \\
\hline Outdoors & $360(350-370)$ & $550(530-660)$ & $310(300-350)$ & ppm & Median (10th-90th percentile) \\
\hline Ammonia & na & 3212 & 1330 & $\mu \mathrm{g} / \mathrm{m}^{3}$ & Median \\
\hline \multicolumn{6}{|l|}{ Relative humidity } \\
\hline In stable & $73(41-84)$ & $79(65-83)$ & $86(58-97)$ & $\mathrm{RH} \%$ & Mean (range) \\
\hline Outdoors & $88(66-94)$ & $76(43-97)$ & na & $\mathrm{RH} \%$ & Mean (range) \\
\hline \multicolumn{6}{|l|}{ Temperature } \\
\hline In stable & $8(7-15)$ & $21(19-24)$ & $8(6-12)$ & ${ }^{\circ} \mathrm{C}$ & Mean (range) \\
\hline Outdoors & $6(5-10)$ & $21(19-30)$ & $6(2-15)$ & ${ }^{\circ} \mathrm{C}$ & Mean (range) \\
\hline Total dust & $210(210-790)$ & $220(100-250)$ & $200(160-290)$ & $\mu \mathrm{g} / \mathrm{m}^{3}$ & Mean (range) \\
\hline Respirable dust & $100(60-270)$ & $70(60-210)$ & $130(40-410)$ & $\mu \mathrm{g} / \mathrm{m}^{3}$ & Mean (range) \\
\hline \multicolumn{6}{|l|}{$\mathrm{PM}_{10}$} \\
\hline In stable & na & $53(34-88)$ & $65(26-159)$ & $\mu \mathrm{g} / \mathrm{m}^{3}$ & Median (10th-90th percentile) \\
\hline Outdoors & na & $47(34-54)$ & na & $\mu \mathrm{g} / \mathrm{m}^{3}$ & Median (10th-90th percentile) \\
\hline \multicolumn{6}{|l|}{ Ultrafine particles } \\
\hline In stable & $8000(5100-13,000)$ & $1500(900-1900)$ & $5400(3000-9000)$ & $\mathrm{Pt} / \mathrm{cm}^{3}$ & Median (10th-90th percentile) \\
\hline Outdoors & $10500(5500-17,500)$ & $2000(1600-2600)$ & $4600(1800-6300)$ & $\mathrm{Pt} / \mathrm{cm}^{3}$ & Median (10th-90th percentile) \\
\hline Horse allergen & 5170 & 750 & 790 & $\mathrm{U} / \mathrm{m}^{3}$ & Median \\
\hline \multicolumn{6}{|c|}{ Microorganisms surface } \\
\hline Bacteria (total) & $110(20-140)$ & $1.6(0.4-2.2)$ & $1.4(1.0-27)$ & $10^{5} / \mathrm{cm}^{2}$ & Median (range) \\
\hline Fungi (total) & $6.6(6.0-8.4)$ & $0.06(0.04-0.1)$ & $0.15(0.06-0.15)$ & $10^{5} / \mathrm{cm}^{2}$ & Median (range) \\
\hline \multicolumn{6}{|c|}{ Microorganisms air } \\
\hline Bacteria (total) & $19(0.9-22)$ & $3.2(0.7-4.7)$ & $21(21-77)$ & $10^{5} / \mathrm{m}^{3}$ & Median (range) \\
\hline Bacteria (CFU) & $0.7(0.2-3.6)$ & $0.03(0.03-0.25)$ & $1.6(1.6-70)$ & $10^{5} / \mathrm{m}^{3}$ & Median (range) \\
\hline Fungi (total) & $3.5(0.1-13)$ & $1.5(1.2-2.7)$ & $6.6(6.6-22)$ & $10^{5} / \mathrm{m}^{3}$ & Median (range) \\
\hline Fungi (CFU) & $0.2(0.002-0.96)$ & $0.04(0.03-0.05)$ & $0.05(0.05-3.8)$ & $10^{5} / \mathrm{m}^{3}$ & Median (range) \\
\hline Endotoxin air & 96 & 85 & 275 & $\mathrm{EU} / \mathrm{m}^{3}$ & Median (range) \\
\hline
\end{tabular}

$C F U$ Colony-forming units, $P M_{10}$ particulate matter with a diameter $<10 \mu \mathrm{m}, n a$ data not available

Round 1 was carried out during the winter before the intervention-no mechanical ventilation present; Round 2 was carried out during the summer before the intervention-no mechanical ventilation was present; Round 3 was carried out during the winter after the interventionmechanical ventilation had been installed

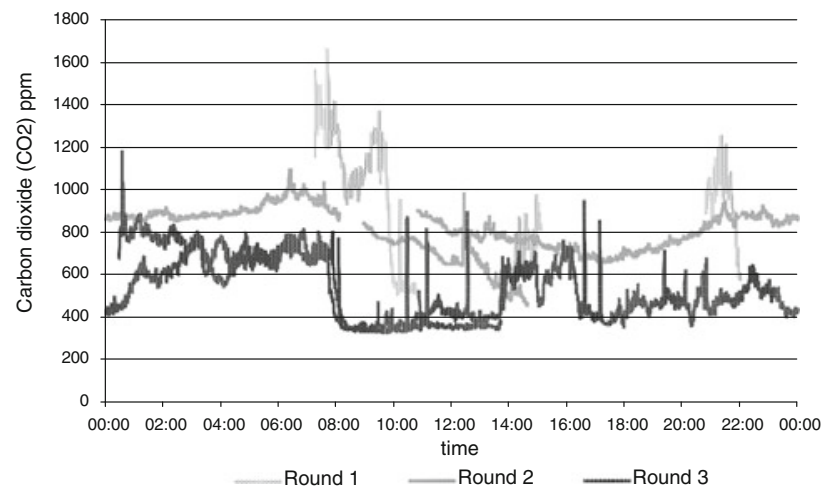

Fig. 2 Level of $\mathrm{CO}_{2}$ at the riding-school stable over a 24-h period in each of Round 1, 2 and 3
Effects of intervention on equine health

In horses, the accumulation of mucus (mucus score according to Gerber scale [32]) was significantly reduced in the winter after the intervention compared to the first winter sampling $(p=0.036)$ (Table 3$)$. Haematology revealed only minor variations that had no clinical relevance. Results from the cytological tests on the BAL showed a slightly increased percentage of neutrophils in two horses after the intervention, of which one also had increased respiratory rate and respiratory sounds. The PCR expression of IL-6 mRNA in BAL cells was significantly lower in the winter after the intervention than in the winter before the intervention (Fig. 3). 
Table 2 Levels of pulmonary function and biomarkers in nasal lavage in stable personnel and riding-students

\begin{tabular}{|c|c|c|c|c|c|c|}
\hline \multirow[t]{2}{*}{ Parameter } & \multicolumn{3}{|l|}{ Stable personnel } & \multicolumn{3}{|l|}{ Riding-students ${ }^{\mathrm{a}}$} \\
\hline & Round $1(n=6)$ & Round $2(n=5)$ & Round $3(n=5)$ & Round $1(n=7)$ & Round $2(n=5)$ & Round $3(n=6)$ \\
\hline $\mathrm{PEF}(\mathrm{L} / \mathrm{min})^{\mathrm{b}}$ & $426(65)$ & $431(45)$ & $407(25)$ & $387(50)$ & $373(45)$ & $416(40)$ \\
\hline FEV1 $(\mathrm{L} / \mathrm{s})^{\mathrm{b}}$ & $3.1(0.3)$ & $3.2(0.2)$ & $2.9(0.1)$ & $2.9(0.3)$ & $2.9(0.3)$ & $3.2(0.25)$ \\
\hline NO (ppb) & 12 & 12 & 11 & 8 & 14 & 13 \\
\hline $\mathrm{ECP}(\mu \mathrm{g} / \mathrm{L})$ & $<2$ & $<2$ & $<2$ & - & - & - \\
\hline MPO $(\mu \mathrm{g} / \mathrm{L})$ & 49 & 50 & 26 & - & - & - \\
\hline Lysozyme (mg/L) & 5.0 & 2.8 & 3.7 & - & - & - \\
\hline Albumin (mg/L) & 7 & $<5$ & $<5$ & - & - & - \\
\hline IL-5 (ng/L) & $<38$ & $<38$ & $<38$ & - & - & - \\
\hline $\mathrm{IFN}-\gamma(\mathrm{ng} / \mathrm{L})$ & 54 & $<25$ & 455 & - & - & - \\
\hline
\end{tabular}

PEF peak expiratory flow, $F E V 1$ forced expiratory volume in $1 \mathrm{~s}, N O$ nitrogen oxide, ECP eosinophil cationic protein, $M P O$ myeloperoxidase, $I L$ interleukin, $I F N$ interferon

${ }^{\text {a }}$ Nasal lavage was not performed on the students

${ }^{\mathrm{b}}$ PEF and FEV1 are the mean of repeated measurements \pm the standard deviation (SD) made during a 2-week period

Table 3 Results from the clinical examination and cytological tests on the bronchoalveolar lavage of the horses

\begin{tabular}{|c|c|c|c|}
\hline & Round 1 & Round 2 & Round 3 \\
\hline \multicolumn{4}{|l|}{ Clinical examination } \\
\hline Respiratory rate & 8 horses $^{\mathrm{a}} \leq 15 / \mathrm{min}$ & $2 / 8$ horses $^{\mathrm{a}} 16-20 / \mathrm{min}$ & $1 / 8$ horses $^{\mathrm{a}} 16-20 / \mathrm{min}$ \\
\hline Auscultation thorax & Normal & Normal & 7 normal, $1 / 8$ horse with respiratory sounds \\
\hline Nasal discharge $(\text { mean } \pm \mathrm{SD})^{\mathrm{b}}$ & $1.57 \pm 0.53$ & $1.43 \pm 0.54$ & $1.29 \pm 0.49$ \\
\hline Spontaneous coughing & 0 & 0 & 0 \\
\hline Cough provocation & All negative & All negative & $1 / 8$ horses positive \\
\hline \multicolumn{4}{|l|}{ Endoscopy } \\
\hline \multicolumn{4}{|l|}{ Mucus in trachea $(\text { mean } \pm \mathrm{SD})^{\mathrm{c}}$} \\
\hline Accumulation & $1.59 \pm 1.37$ & $1.03 \pm 0.79$ & $0.46 \pm 0.51 *$ \\
\hline Localization and stickness & $1.77 \pm 0.61$ & $1.50 \pm 0.48$ & $1.45 \pm 0.77$ \\
\hline Apparent viscosity & $2.83 \pm 0.41$ & $2.24 \pm 0.82$ & $1.50 \pm 0.76$ \\
\hline Colour & $3.37 \pm 0.45$ & $3.76 \pm 1.10$ & $4.3 \pm 0.58$ \\
\hline Increased thickness of tracheal septum & 1 & 0 & 0 \\
\hline \multicolumn{4}{|l|}{ Bronchoalveolar lavage } \\
\hline \multirow[t]{2}{*}{ Neutrophils in BAL (\%) } & $<10 \%$ & $<10 \%$ & $1 / 8$ horses $11 \%$ \\
\hline & & & $1 / 8$ horses $24 \%$ \\
\hline
\end{tabular}

*Significantly lower $(p<0.05)$ mucus accumulation in trachea at Round 3 compared to Round 1

$B A L$ Bronchoalveolar lavage

a Total number of horses examined $=8$

${ }^{\mathrm{b}}$ Clear nostrils $=1$, serous discharge $=2$, purulent discharge $=3$

c According to Gerber scale [32]

\section{Discussion}

The installation of a balanced mechanical ventilation system with supply and exhaust air resulted in reduced levels of $\mathrm{CO}_{2}$, ammonia, ultrafine particles and horse allergen. The fact that the $\mathrm{CO}_{2}$ level was halved shows that the installation of mechanical ventilation was effective in improving the air quality in the stable. The effect of this intervention was evaluated by comparing two successive winter samplings. We also compared winter values with summer values, which may in many cases, be the best values anticipated in this stable. 


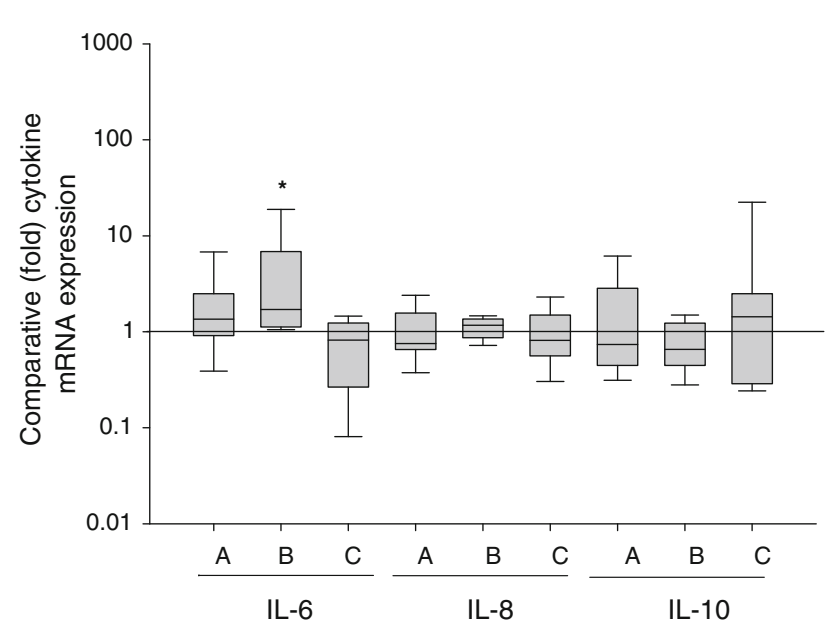

Fig. 3 Comparison of the relative (fold) increase (with interquartile range) in cytokine ( $I L$ interleukin) mRNA expression in horse bronchoalveolar lavage cells on different sampling occasions. The horizontal line represents the medial line. The value 1 on the $y$-axis represents the theoretical point where results from different rounds are identical $\left(\Delta \Delta C_{\mathrm{T}}=0,2^{-\Delta \Delta C_{\mathrm{T}}}=2^{0}=1\right) . A$ Round 1 vs. Round 2, $B$ Round 1 vs. Round 3, $C$ Round 3 vs. Round 2. Asterisk Significant difference in median value of 1

We choose to compare values before and after the intervention during the winter season, when the indoor climate in a stable is generally at its worst. In winter, it is cold and damp outside, which means that natural ventilation in a stable is kept at its lowest, with closed doors and windows [33]. Following the installation of mechanical ventilation, the air exchange rate was increased to at least $400-500 \mathrm{~L} / \mathrm{s}$ at the lowest indoor temperature of about $+5^{\circ} \mathrm{C}$. This means a much better exchange rate than can be expected with natural ventilation. The flow has to be reduced at low outdoor temperatures (i.e. -10 to $-20^{\circ} \mathrm{C}$ ) to prevent the indoor temperature from falling below zero. It is too costly to warm up the supply air in a stable, which is why ventilation systems are run in this manner in a cold climate, such as in Sweden.

Since the mechanical ventilation was running $24 \mathrm{~h} /$ day and automatically regulated by the indoor temperature in the stable, with a maximum airflow $(2200 \mathrm{~L} / \mathrm{s})$ at high temperatures, i.e. during the summer, and a minimum flow $(400 \mathrm{~L} / \mathrm{s})$ at $5^{\circ} \mathrm{C}$, the ventilation system was running at a low capacity during the second winter sampling (Round 3) as the mean temperature was $8^{\circ} \mathrm{C}$. This could explain why some hygienic measures showed greater seasonal effects than the comparison before and after the intervention and indicates that summer values were sometimes lower than winter values (Round $2<$ Round 3) despite the use of only natural ventilation. Another explanation for why the measurements of dust, microorganisms and endotoxin were not reduced by the intervention could be because most hygienic measurements were made during peak exposures, such as cleaning and feed delivery. Peak values are probably less affected by low- to moderate ventilation rates. However, $\mathrm{PM}_{10}$ particle levels were low compared with those reported for other stables and pig farms [1, 12, 3335], with median values ranging between 53 and $65 \mu \mathrm{g} / \mathrm{m}^{3}$ in our study. It is well known that there is a substantial measurement error and also a large day-to day variability in many hygienic measurements [36].

None of our subjects reported a diagnosis of asthma. However, one of the stable personnel reported the use of asthma medication before- but not after-the intervention, implying a better quality of air after the installation of the mechanical ventilation. Two students reported hay-fever, but none of the personnel. In a previous study, we described a possible disregard among stable personnel having respiratory problems [10]. In the present study, we found a status quo regarding reported symptoms and airway measurements in personnel and students. These results might be anticipated among a relatively healthy study population with environmentally-related symptoms being better than expected.

In horses, decreased tracheal mucous was the strongest indication of reduced airway inflammation after the intervention. Cytokine IL-6 is a pre-inflammatory marker and indicator of exposure to the stable environment per se. The expression of IL-6 mRNA can be associated with increased mucus secretion due to the stimulation of mucin genes, such as MUC5AC, in horses [37, 38]. Therefore, a decreased amount of mucous in the trachea together with a lower expression of IL-6 mRNA in BAL cells may indicate an improvement in the health of the horse's airways after the intervention. However, after the intervention, one of the eight horses had an increased respiratory rate and respiratory sounds. This horse, together with another horse, had a mild elevation in BAL neutrophils after the intervention (Table 3).

In summary, the overall clinical outcome in horses indicates less airway inflammation. Why this was not observed in humans could be due to the fact that horses spend substantially longer times in the stable.

\section{Conclusions}

Hygienic measurements showed an increased air exchange rate, verified by reduced levels of $\mathrm{CO}_{2}$, ammonia, ultrafine particles and horse allergen. Taken together, these results indicate an improved air quality. No significant effects were observed in humans, but there was a tendency towards reduced inflammation markers. The overall clinical effects in horses may indicate a lower impact on the airways after the intervention. 
Acknowledgments We would like to thank Mabtech AB, Stockholm, Sweden, which generously supplied the monoclonal antibody reagents for the horse allergen ELISA. This work received funding from Swedish Farmer's Foundation for Agricultural Research and Foundation for Horse Research.

\section{References}

1. Malmberg P. Health effects of organic dust exposure in dairy farmers. Am J Ind Med. 1990;17(1):7-15.

2. Linaker C, Smedley J. Respiratory illness in agricultural workers. Occup Med (Lond). 2002;52(8):451-9.

3. Omland O, Sigsgaard T, Hjort C, Pedersen OF, Miller MR. Lung status in young Danish rurals: the effect of farming exposure on asthma-like symptoms and lung function. Eur Respir J. 1999; 13(1):31-7.

4. Lembke B, Janson C, Norbäck D, Rask-Andersen A. High risk of adult-onset asthma and work-related wheeze in farmers despite low prevalence of asthma in young farmers. Int $\mathbf{J}$ Tuberc Lung Dis. 2004;8(11):1285-91.

5. Pickrell J. Hazards in confinement housing-gases and dusts in confined animal houses for swine, poultry, horses and humans. Vet Hum Toxicol. 1991;33(1):32-9.

6. Pirie RS, Collie DDS, Dixon PM, McGorum BC. Inhaled endotoxin and organic dust particulates have synergistic proinflammatory effects in equine heaves (organic dust-induced asthma). Clin Exp Allergy. 2003;33(5):676-83.

7. Vogelzang PF, van der Gulden JW, Folgering H, Kolk JJ, Heederik D, Preller L, et al. Endotoxin exposure as a major determinant of lung function decline in pig farmers. Am J Respir Crit Care Med. 1998;157(1):15-8.

8. Spurzem JR, Romberger DJ, Von Essen SG. Agricultural lung disease. Clin Chest Med. 2002;23(4):795-810.

9. Charavaryamath C, Singh B. Pulmonary effects of exposure to pig barn air. J Occup Med Toxicol. 2006;1:10.

10. Elfman L, Riihimäki M, Pringle J, Wålinder R. Influence of horse stable environment on human airways. J Occup Med Toxicol. 2009;4:10.

11. Nardoni S, Mancianti F, Sgorbini M, Taccini F, Corazza M. Identification and seasonal distribution of airborne fungi in three horse stables in Italy. Mycopathologia. 2005;160(1):29-34.

12. Samadi S, Wouters IM, Houben R, Jamshidifard A, Van Eerdenburg F, Heederik DJJ. Exposure to inhalable dust, endotoxins, beta(1-3)-glucans, and airborne microorganisms in horse stables. Ann Occup Hyg. 2009;53(6):595-603.

13. Tutluoglu B, Atiş S, Anakkaya AN, Altug E, Tosun GA, Yaman M. Sensitization to horse hair, symptoms and lung function in grooms. Clin Exp Allergy. 2002;32(8):1170-3.

14. Gallagher LM, Crane J, Fitzharris P, Bates MN. Occupational respiratory health of New Zealand horse trainers. Int Arch Occup Environ Health. 2007;80(4):335-41.

15. Mazan MR, Svatek J, Maranda L, Christiani D, Ghio A, Nadeau $\mathrm{J}$, et al. Questionnaire assessment of airway disease symptoms in equine barn personnel. Occup Med (Lond). 2009;59(4):220-5.

16. Holcombe SJ, Jackson C, Gerber V, Jefcoat A, Berney C, Eberhardt $\mathrm{S}$, et al. Stabling is associated with airway inflammation in young Arabian horses. Equine Vet J. 2001;33(3):244-9.

17. Kirchner M, Braeutigam S, Ferm M, Haas M, Hangartner M, Hofschreuder P, et al. Field intercomparison of diffusive samplers for measuring ammonia. J Environ Monit. 1999;1(3):259-65.

18. Emenius G, Larsson PH, Wickman M, Härfast B. Dispersion of horse allergen in the ambient air, detected with sandwich ELISA. Allergy. 2001;56(8):771-4.
19. Palmgren U, Ström G, Blomqvist G, Malmberg P. Collection of airborne micro-organisms on ncleopore filters, estimation and analysis-CAMNEA method. J Appl Bacteriol. 1986;61:401-6.

20. Vagn Jensen. The dilution plate count technique for the enumeration of bacteria and fungi in soil. Zbl Bakteriol Parasitenkde. 1962;116:13-32.

21. American Thoracic Society (ATS) American Thoracic Society Medical Section of the American Lung Association standardization of spirometry. 1994 update. Am J Respir Crit Care Med. 1995; 152:1107-36.

22. Anees W, Gannon PF, Huggins V, Pantin CFA, Burge PS. Effect of peak expiratory flow data quantity on diagnostic sensitivity and specificity in occupational asthma. Eur Respir J. 2004;23(5): $730-4$.

23. Wålinder R, Norbäck D, Wieslander G, Smedje G, Erwall C, Venge $P$. Nasal patency and biomarkers in nasal lavage-the significance of air exchange rate and type of ventilation in schools. Int Arch Occup Environ Health. 1998;71(7):479-86.

24. Venge P, Håkansson L, Peterson C. Eosinophil activation in allergic disease. Int Arch Allergy Appl Immunol. 1987;82:333-7.

25. Venge P. Soluble markers of allergic inflammation. Allergy. 1994;49:1-8.

26. Raphael G, Jeney E, Baraniuk J, Kim I, Meredith S, Kaliner M. Pathophysiology of rhinitis. Lactoferrin and lysozyme in nasal secretions. J Clin Invest. 1989;84:1528-35.

27. Raphael G, Igarashi Y, White M, Kaliner M. The pathophysiology of rhinitis. V. Sources of protein in allergen- induced nasal secretions. J Allergy Clin Immunol. 1991;88:33-42.

28. Romagnani S. Type 1T-helper and type 2 T-helper cells: function, regulation and role in protection and disease. Int J Clin Lab Res. 1991;21:152-8.

29. Riihimäki M, Raine A, Elfman L, Pringle J. Markers of respiratory inflammation in horses in relation to seasonal changes in air quality in a conventional racing stable. Can J Vet Res. 2008; 72(5):432-9.

30. Solymar L, Aronsson PH, Bake B, Bjure J. Nitrogen single breath test, flow-volume curves and spirometry in healthy children, 7-18 years of age. Eur J Respir Dis. 1980;61(5):275-86.

31. Hedenström H, Malmberg P, Agarwal K. Reference values for lung function tests in females. Regression equations with smoking variables. Bull Eur Physiopathol Respir. 1985;21(6):551-7.

32. Gerber V, Straub R, Marti E, Hauptman J, Herholz C, King M, et al. Endoscopic scoring of mucus quantity and quality: observer and horse variance and relationship to inflammation, mucus viscoelasticity and volume. Equine Vet J. 2004;36(7):576-82.

33. Webster AJ, Clarke AF, Madelin TM, Wathes CM. Air hygiene in stables. 1: Effects of stable design, ventilation and management on the concentration of respirable dust. Equine Vet J. 1987;19(5):448-53.

34. Crichlow EC, Yoshida K, Wallace K. Dust levels in a riding stable. Equine Vet J. 1980;12(4):185-8.

35. Clarke AF. Stable dust-threshold limiting values, exposures variables and host risk factors. Equine Vet J. 1993;25(3):172-4.

36. O’Meara T, Tovey E. Monitoring personal allergen exposure. Clin Rev Allergy Immunol. 2000;18:341-95.

37. Gerber V, Robinson NE, Venta RJ, Rawson J, Jefcoat AM, Hotchkiss JA. Mucin genes in horse airways: MUC5AC, but not MUC2, may play a role in recurrent airway obstruction. Equine Vet J. 2003;35(3):252-7.

38. Chen Y, Thai P, Zhao Y, Ho Y, DeSouza M. Stimulation of airway mucin gene expression by interleukin (IL-17) through IL-6. J Biol Chem. 2003;2778:17036-43. 